\title{
Produção de mudas de Etlingera elatior (Jack) R.M. Sm. através da cultura de tecidos vegetais in vitro
}

RESCAROLLI, C.L.S. ; ZAFFARI, G.R.

Universidade do Vale do Itajaí, CTTMar, Caixa Postal 360, Itajaí, SC, CEP 88302-202, *cristine.bio@gmail.com; gzaffari@epagri.sc.gov.br

\begin{abstract}
RESUMO: O uso de produtos naturais para o tratamento de doenças é algo que o ser humano já está habituado a realizar desde o início dos tempos. A utilização de Etlingera elatior (Bastão do Imperador), uma herbácea muito comum nos jardins e em áreas de banhado, para o tratamento de dores musculares e reumatismo é citada pela cultura popular, o que incentivou a indústria farmacêutica a começar a investir nos estudos sobre sua atividade. Porém, a produção de biomassa através de plantas sadias e de alta qualidade ainda é incipiente. $O$ uso da biotecnologia vegetal, especialmente a propagação vegetativa in vitro, permite a produção em larga escala de mudas e/ou biomassa vegetal, de alta qualidade genética e fitossanitária, em curto espaço de tempo e pequena área física. O objetivo deste trabalho foi avaliar o efeito de agentes desinfestantes na obtenção de explantes assépticos, da composição do meio de cultura e do seccionamento do rizoma no desenvolvimento, multiplicação e enraizamento das plantas in vitro, visando estabelecer o processo de micropropagação. Gemas laterais foram submetidas à desinfestação com etanol e hipoclorito de cálcio e de sódio. Os rizomas assépticos foram seccionados longitudinalmente e multiplicados em meio de cultura MS adicionado de BAP $(0,0 ; 1,0$ e 2,0 mg L-1). O estabelecimento das culturas assépticas a partir do uso de etanol $70 \%, \mathrm{NaClO} 1 \%$ e CaClO 2 e $5 \%$ proporcionaram de 10 a $40 \%$ de sobrevivência dos explantes. A taxa de multiplicação obtida nos rizomas, inteiros e seccionados longitudinalmente e cultivados em meio MS, não apresentou diferença significativa para o número de brotos. Já o cultivo do rizoma seccionado em meio MS adicionado de $1,0 \mathrm{mg} \mathrm{L}^{-1}$ de BAP resultou em aumento significativo no número de brotos em relação a rizoma inteiro na mesma concentração de BAP. As plantas cultivadas na presença de BAP apresentaram redução do número de raízes a partir de rizomas inteiros. Apesar do efeito do seccionamento do rizoma e da concentração de BAP, no número de brotos e raízes, as plantas não mostraram diferença no crescimento da planta e das raízes. $A$ micropropagação da espécie Etlingera elatior é possível, possibilitando a produção de mudas em larga escala.
\end{abstract}

Palavras-chave: micropropagação, planta medicinal, bastão do imperador

ABSTRACT: Etlingera elatior seedling production through in vitro tissue culture. The use of natural products to treat diseases has been common for humans since the beginning of times. Etlingera elatior (torch ginger), an herbaceous species very common in gardens and muddy areas, has been cited by the popular culture as treatment for muscular pains and rheumatism, which has stimulated the pharmaceutical industry to start investing in studies on its activity. However, phytomass production by high-quality healthy plants is still incipient. The utilization of plant biotechnology, specially in vitro vegetative propagation, allows the large-scale production of seedlings and/or phytomass of high genetic and phytosanitary quality in a short time and small area. The aim of this work was to evaluate the action of disinfectant agents on the production of aseptic explants, as well as the effect of culture medium composition and rhizome splitting on the development, multiplication and rooting of plants in vitro in order to establish the micropropagation process. Lateral buds were disinfected with ethanol and calcium and sodium hypochlorite. Aseptic rhizomes were longitudinally sectioned and multiplied in MS culture medium containing $\operatorname{BAP}\left(0.0,1.0\right.$ and $\left.2.0 \mathrm{mg} \mathrm{L}^{-1}\right)$. The establishment of aseptic cultures by using $70 \%$ ethanol, $1 \% \mathrm{NaClO}$ and $1 \%$ and $5 \%$ $\mathrm{CaClO}$ resulted in 10 to $40 \%$ explant survival. The multiplication rate obtained for whole and

Recebido para publicação em 19/05/2008

Aceito para publicação em 31/10/2008

Rev. Bras. PI. Med., Botucatu, v.11, n.2, p.190-195, 2009. 
longitudinally sectioned rhizomes cultivated in MS medium did not present significant difference for sprout number. However, sectioned rhizome cultivated in MS medium added of $1.0 \mathrm{mg} \mathrm{L}^{-1} \mathrm{BAP}$ had a significant increase in sprout number, relative to whole rhizomes at the same BAP concentration. In the presence of BAP, there was a reduction in root number for whole rhizomes. Although rhizome splitting and BAP concentration affected sprout and root number, there was no difference in the growth of plants and roots. Thus, Etlingera elatior micropropagation is possible, allowing the large-scale production of seedlings.

Key words: micropropagation, medicinal plant, torch ginger

\section{INTRODUÇÃO}

O uso de produtos naturais pelo ser humano remonta à idade antiga. Sabe-se que é muito mais provável encontrar atividade biológica em plantas orientadas pelo seu uso na medicina popular do que em plantas escolhidas ao acaso na natureza. Cerca de $75 \%$ dos compostos puros naturais, empregados na indústria farmacêutica, foram isoladas, seguindo recomendações da medicina popular (Yunes \& Calixto, 2001). A espécie Etlingera elatior, popularmente conhecida como Bastão do Imperador, planta ornamental e medicinal, tem sido indicada segundo a medicina popular para o tratamento de dores musculares e reumatismo. Pertencente à família Zingiberaceae, possui ampla dispersão nos trópicos e subtrópicos de todo mundo, principalmente no sudeste da Ásia (Joly, 1998).

Os aspectos mais críticos na produção de plantas medicinais para a utilização terapêutica são, sem dúvida, a quantidade e a qualidade da matériaprima vegetal. Vários fatores climáticos afetam diretamente a qualidade, a eficácia e a segurança do produto final. Para evitar tais problemas, e sobretudo, evitar o extrativismo descontrolado, as indústrias vêm atuando no sentido de aumentar a quantidade e melhorar a qualidade dessa matéria-prima através do cultivo de plantas medicinais em larga escala. Além de poder eliminar variações oriundas de fatores como o clima, nutrientes e luminosidade, a produção massal de plantas permite selecionar espécies com maior teor de princípios ativos, controlar pragas, ou ainda o que é fundamental, evitar a contaminação por metais pesados, inseticidas e outros fatores que podem influenciar na eficácia, qualidade e segurança clínica dos medicamentos fitoterápicos (Siani, 2003).

A produção massal de plantas medicinais pode ser obtida através da micropropagação in vitro, método bastante eficiente quando se trata de produção de mudas em larga escala, fornecendo matéria-prima de alta qualidade genética e fitossanitária, em curto espaço de tempo. O presente trabalho objetivou avaliar a viabilidade do cultivo in vitro de Etlingera elatior visando à produção massal de mudas, como fonte de matéria-prima para utilização terapêutica.

\section{MATERIALE MÉTODO}

O estudo foi conduzido no Laboratório de Cultivo Celular Vegetal, no Centro de Ciências Tecnológicas da Terra e do Mar, da Universidade do Vale do Itajaí. Os materiais utilizados como explantes foram gemas laterais de Etilingera elatior provenientes de plantas matrizes em boas condições fitossanitárias, mantidas a campo, do banco de germoplasma da Empresa de Pesquisa Agropecuária e Extensão Rural de Santa Catarina (Epagri) - Estação Experimental de Itajaí.

Os materiais utilizados como fonte de explante foram gemas laterais retiradas em forma de cubos com tamanho aproximado de $1 \mathrm{~cm}^{3}$. Após seccionadas, as gemas foram imediatamente imersas em água destilada e submetidas à prédesinfestação em bancada. As gemas laterais foram lavadas em água corrente com detergente neutro e água destilada sob agitação, imersos em solução desinfestante contendo benomyl $\left(0,5 \mathrm{~g} \mathrm{~L}^{-1}\right)+$ mancozeb $\left(2,0 \mathrm{~g} \mathrm{~L}^{-1}\right)+$ sulfato de estreptomicina (180 $\left.\mathrm{mg} \mathrm{L}^{-1}\right)$, por 20 minutos, e posteriormente em $\mathrm{CaClO}$ $4 \%$ por 2 minutos. Após a pré-desinfestação foram realizados cinco tratamentos de desinfestação em câmara de fluxo laminar com Etanol $70 \%$ e CaClO $5 \%$ (Tabela 1). O número de repetições variou de 08 a 15 explantes por tratamento, onde cada repetição consistiu de um explante por tubo.

As gemas que apresentaram contaminação após duas semanas de cultivo, foram submetidas à re-desinfestação (Tabela 1), com imersão por 15 segundos em etanol $70 \%, 5$ minutos em NaClO 1\% e 10 minutos em $\mathrm{CaClO} 2 \%$ e posteriormente, os explantes dos tratamentos de desinfestação e redesinfestação, foram inoculados em meio de cultura de Murashige \& Skoog (1962) (MS) com $9 \mathrm{~g} \mathrm{~L}^{-1}$ de ágar e $30 \mathrm{~g} \mathrm{~L}^{-1}$ de sacarose, adicionado de $0,5 \mathrm{mg} \mathrm{L}^{-1}$ de BAP. Após 100 dias de incubação, os rizomas das plantas estabelecidas assepticamente foram utilizados nos experimentos da fase seguinte. Os tratamentos da fase de proliferação consistiram de rizomas inteiros (RI) ou seccionados longitudinalmente ao meio (RS) (Tabela 2) e inoculados em meio sólido de Murashige \& Skoog (1962) (MS) na ausência e 
TABELA 1. Tempo de imersão dos explantes aos agentes desinfestantes químicos utilizados no processo de desinfestação e re-desinfestação em câmara de fluxo laminar de gemas laterais de Etlingera elatior.

\begin{tabular}{|c|c|c|c|}
\hline Tratamento & Etanol $70 \%$ (min) & $\mathrm{CaCl}$ & $5 \%$ (min) \\
\hline TA01 & 1 & & 30 \\
\hline TA02 & 2 & & 25 \\
\hline TA03 & 3 & & 20 \\
\hline TA04 & 4 & & 15 \\
\hline \multirow[t]{2}{*}{ TA05 } & 5 & & 10 \\
\hline & Etanol $70 \%$ & $\mathrm{NaClO} 1 \%$ & CaClO $2 \%$ \\
\hline Re-desinfestação & $15 \mathrm{seg}$ & $5 \mathrm{~min}$ & $\min$ \\
\hline
\end{tabular}

presença de BAP (6-benzilaminopurina) visando diminuir a dominância apical.

Foram utilizadas seis repetições por tratamento e um explante por parcela, durante 45 dias. As culturas foram mantidas em sala de crescimento sob temperatura de $28 \pm 2^{\circ} \mathrm{C}$, e fotoperíodo de 16 horas com intensidade luminosa de 40 a $50 \mu \mathrm{mol} \mathrm{m}^{-2} \mathrm{~s}^{-1}$. Os dados obtidos nos diferentes ensaios foram submetidos à análise de variância e as médias foram comparadas pelo teste de Tukey ao nível de significância de $5 \%$.

TABELA 2. Meio de cultura sólido de Murashige \& Skoog (1962) (MS), adicionado de diferentes concentrações da citocinina BAP, com rizomas inteiros (RI) ou seccionados longitudinalmente (RS) para a fase de proliferação de plântulas de Etlingera elatior.

\begin{tabular}{ccc}
\hline Tratamentos & $\begin{array}{c}\text { Condição do } \\
\text { rizoma }\end{array}$ & $\begin{array}{c}\text { Regulador de } \\
\text { crescimento }\end{array}$ \\
\hline TP01 & RI & BAP mg L $^{-1}$ \\
TP02 & RI & 0 \\
TP03 & RI & 1,0 \\
TP04 & RS & 0 \\
TP05 & RS & 1,0 \\
TP06 & RS & 2,0 \\
\hline
\end{tabular}

\section{RESULTADOE DISCUSSÃO}

O sucesso na obtenção de explantes assépticos para o estabelecimento da cultura in vitro depende da eficiência da combinação dos agentes químicos, das concentrações e dos tempos de exposição em relação ao nível de contaminação dos tecidos. A exposição das gemas laterais de Etlingera elatior aos tratamentos de desinfestação resultou em níveis de contaminação que variaram de 25,00 a $66,67 \%$ e de 10,00 a $75,00 \%$ para bactérias e fungos, respectivamente (Tabela 3). O aumento gradual do tempo de exposição dos explantes ao Etanol $70 \%$ (1, 2, 3 e 4 minutos) combinado com a diminuição gradual do tempo de exposição ao $\mathrm{CaClO} 5 \%$ (30, 25,20 e 15 minutos), apresentou uma tendência de redução do nível de contaminação por bactérias, e um aumento da contaminação por fungos. Entretanto, a imersão dos explantes em Etanol $70 \%$ por 5 minutos, e $\mathrm{CaClO} 5 \%$ por 10 minutos (TA05) apresentou menor eficiência na eliminação de bactérias $(60,00 \%)$ e um aumento na eficiência do controle de fungos $(20,00 \%)$. Provavelmente a exposição das gemas laterais por menos de 15 minutos ao $\mathrm{CaClO}$ $5 \%$ e por 4 minutos ou mais em etanol $70 \%$ torna menos eficiente à eliminação de bactérias.

Órgãos de plantas que crescem sob o solo não são os melhores explantes para iniciar uma cultura devido à alta taxa de contaminação (Hussey, 1975 a, b), como é o caso das gemas laterais de Etlingera elatior. Segundo Kane et al. (2000) e Schwertner \& Zaffari (2003), outros fatores como o tamanho inicial do explante e suas características morfológicas podem interferir na eficiência do etanol e do hipoclorito de cálcio na eliminação dos agentes contaminantes. Enjalric et al. (1988) obtiveram 21\% de culturas assépticas a partir de gemas axilares de Hevea com $3 \mathrm{~mm}, 42 \%$ a partir de meristemas com $6 \mathrm{~mm}$, e $74 \%$ a partir de ápices caulinares com 1 $\mathrm{mm}$. Por outro lado, Gorecka (1987) teve dificuldade de obter culturas assépticas a partir de meristemas de gemas laterais de raízes de Cochlearia armoracia. A obtenção de culturas assépticas de Cochlearia armoracia só foi possível a partir de explantes foliares submetidos durante 5 minutos em $\mathrm{CaClO} 2,75 \%$ e 2 minutos em etanol $70 \%$.

O tratamento de re-desinfestação de gemas contaminadas por bactérias, após duas semanas de cultivo in vitro, utilizando Etanol $70 \%$ por 15 segundos; $\mathrm{NaClO} 1 \%$ por 5 minutos e $\mathrm{CaClO} 2 \%$ por 10 minutos, também apresentou elevada taxa de contaminação por bactérias $(50,00 \%)$. Entretanto, apesar do maior 
TABELA 3. Porcentagem de contaminação e sobrevivência das gemas laterais de Etlingera elatior submetidas à desinfestação, e inoculadas em meio Murashige \& Skoog (1962) (MS), adicionado de 0,5 $\mathrm{mg} \mathrm{L}^{-1}$ de Benzilaminopurina (BAP), após 100 dias de cultivo in vitro.

\begin{tabular}{|c|c|c|c|c|}
\hline \multirow{3}{*}{ Tratamento } & \multicolumn{4}{|c|}{ Contaminação } \\
\hline & \multirow{2}{*}{$\begin{array}{c}\text { Número de } \\
\text { observações }^{* *}\end{array}$} & \multicolumn{2}{|c|}{$(\%)$} & \multirow{2}{*}{$\begin{array}{c}\text { Sobrevivência } \\
(\%)\end{array}$} \\
\hline & & Bactéria & Fungo & \\
\hline TA01 - etanol 70\% $1 \mathrm{~min}+\mathrm{CaClO} 5 \% 30 \mathrm{~min}$ & 15 & 66,67 & 13,33 & 20,00 \\
\hline TA02 - etanol $70 \% 2 \mathrm{~min}+\mathrm{CaClO} 5 \% 25 \mathrm{~min}$ & 10 & 30,00 & 40,00 & 30,00 \\
\hline TA03 - etanol $70 \% 3 \mathrm{~min}+\mathrm{CaClO} 5 \% 20 \mathrm{~min}$ & 13 & 38,46 & 30,77 & 30,77 \\
\hline TA04 - etanol 70\% $4 \mathrm{~min}+\mathrm{CaClO} 5 \% 15 \mathrm{~min}$ & 08 & 25,00 & 75,00 & 0,00 \\
\hline TA05 - etanol 70\% $5 \mathrm{~min}+\mathrm{CaClO} 5 \% 10 \mathrm{~min}$ & 10 & 60,00 & 20,00 & 10,00 \\
\hline $\begin{array}{c}\text { Re-desinfestação* - etanol 70\% } 15 \mathrm{seg}+ \\
\quad \mathrm{NaClO} 1 \% 5 \mathrm{~min}+\mathrm{CaClO} 2 \% 10 \mathrm{~min}\end{array}$ & 10 & 50,00 & 10,00 & 40,00 \\
\hline
\end{tabular}

$\left({ }^{*}\right)$ Desinfestação dos explantes contaminados por bactérias $\left.\quad{ }^{* *}\right)$ Número de observações $=$ número de repetições por tratamento

tempo de exposição dos tecidos aos agentes químicos, considerando-se a desinfestação e redesinfestação, este tratamento apresentou a maior taxa de sobrevivência de culturas assépticas. A exposição das gemas ao etanol $70 \%$ e aos compostos a base de cloro, hipoclorito de sódio e de cálcio, não foi efetivo na eliminação de bactérias. Segundo Grattapaglia \& Machado (1998), essas contaminações bacterianas são endógenas e a destruição destes microrganismos se torna difícil e sério problema nas fases de multiplicação das culturas. Os percentuais de sobrevivência de explantes assépticos obtidos nos tratamentos TA01, TA02 e TA03 apresentaram uma correlação positiva com o aumento do tempo de exposição ao etanol $70 \%$. Entretanto, o aumento no tempo de exposição das gemas laterais de 3 para 4 e 5 minutos ao etanol $70 \%$ resultou em diminuição da sobrevivência de explantes assépticos.

A sensibilidade dos tecidos dos explantes aos agentes desinfestantes, etanol e hipoclorito, varia com a espécie e com o tipo de tecido. Khosh-Khui \& Sink (1982 a) verificaram que meristemas de rosa foram mais sensíveis quando expostos ao hipoclorito de sódio $5,25 \%$ por 10 a 15 minutos do que as gemas laterais. Estudos com ápices caulinares de Vitis apresentaram elevada taxa de mortalidade quando tratados com hipoclorito de sódio (Martinez \& Tizio, 1989). Entretanto, o estabelecimento de culturas assépticas de Cordyline $s p$. só foi possível a partir de gema apical, uma vez que a retirada das bainhas das gemas laterais dos segmentos caulinares deixa cicatrizes, por onde pode ocorrer a penetração de agentes desinfestantes, levando à morte dos meristemas axilares (Debergh \& Maene, 1981). Gemas de Seringa e de outras plantas ornamentais arbustivas são muito sensíveis ao hipoclorito quando coletadas antes da primavera, porém gemas extraídas um ano após foram mais resistentes às soluções de desinfestação, porém apresentaram elevada contaminação.

A indução de brotos na fase de proliferação foi estimulada significativamente pela diminuição da dominância apical, através do seccionamento do rizoma e da adição de citocinina ao meio de cultura (Tabela 4). Resultados semelhantes foram obtidos por Tanaka et al. (2006) que verificaram que a decapitação do ápice caulinar diminuiu a concentração de ácido indolacético (AIA) e que as citocininas provenientes da raiz induziram o desenvolvimento de gemas e novos ápices ativos. Entretanto, o cultivo de rizoma seccionado em meio MS com o dobro da concentração de citocinina (TP06), resultou numa redução significativa no número de brotos quando comparado ao tratamento TP05. Na maioria das plantas superiores, o crescimento da gema apical inibe o crescimento das gemas laterais, enquanto que a aplicação direta de citocininas estimula a divisão celular e o crescimento dessas gemas, suprimindo o efeito inibitório do ápice caulinar (Taiz \& Zeiger, 2004; Souza, 2006; Zaffari et al., 2000). Provavelmente, a não indução do desenvolvimento das gemas laterais na espécie $E$. elatior se deve à alta dominância apical das plântulas, e/ou a ineficiência dos níveis de citocinina presente no meio de cultura em alterar a 
TABELA4. Valores médios do número de brotos e raízes e do crescimento dos brotos e raízes de rizomas inteiros (RI) e seccionados longitudinalmente ao meio (RS) de Etlingera elatior durante a fase de proliferação, cultivadas em meio de cultura Murashige \& Skoog (1962) (MS) adicionado ou não de diferentes concentrações de Benzilaminopurina (BAP), após 45 dias de cultivo in vitro.

\begin{tabular}{|c|c|c|c|c|}
\hline Tratamento & $\begin{array}{l}\text { Número } \\
\text { de brotos }\end{array}$ & $\begin{array}{l}\text { Crescimento } \\
\text { das Plantas }\end{array}$ & Número de Raízes & $\begin{array}{c}\text { Crescimento } \\
\text { das Raízes (cm) }\end{array}$ \\
\hline TP01 (MS + RI) & $3,17 b$ & $2,56 \mathrm{a}$ & $6,83 a$ & $4,07 \mathrm{a}$ \\
\hline TPO2 (MS + RI + 1,0 BAP $\left.\mathrm{mg} \mathrm{L}^{-1}\right)$ & $2,83 b$ & $3,10 a$ & $2,84 a b$ & $2,14 a$ \\
\hline TPO3 (MS + RI + 2,0 BAP $\left.\mathrm{mg} \mathrm{L}^{-1}\right)$ & $4,50 \mathrm{ab}$ & 1,62 a & $2,00 b$ & 1,88 a \\
\hline TP04 (MS + RS) & $2,83 b$ & $2,88 a$ & $5,50 \mathrm{ab}$ & $4,87 \mathrm{a}$ \\
\hline TP05 (MS + RS + 1,0 BAP mg L' & $6,50 \mathrm{a}$ & $2,56 \mathrm{a}$ & $5,25 \mathrm{ab}$ & $3,03 \mathrm{a}$ \\
\hline TP06 (MS + RS + 2,0 BAP mg L $\left.{ }^{-1}\right)$ & $3,60 \mathrm{~b}$ & $2,56 a$ & $2,40 a b$ & 2,91 a \\
\hline
\end{tabular}

Médias seguidas da mesma letra não diferem significativamente entre si pelo teste de Tukey $(p<0,05)$.

relação auxinas/citocininas nos tecidos. A adição de fitorreguladores em culturas vegetais in vitro tem o objetivo principal de suprir as possíveis deficiências dos teores endógenos de hormônios nos explantes que se encontram isolados das regiões produtoras na planta-matriz e também direcionar uma resposta morfogenética desejável (George, 1993). Entretanto, o tempo de permanência de apenas 45 dias na presença de citocinina parece ser o período máximo possível, uma vez que se observou o amarelecimento das folhas.

A adição da citocinina BAP não promoveu um efeito significativo no crescimento das plantas, mesmo com o dano mecânico no rizoma e com o aumento da concentração no meio de cultura. Apesar de a citocinina estimular o crescimento da parte aérea, a obtenção de baixa resposta morfogenética no crescimento das plantas pode ser devido à falta de ação do regulador de crescimento, uma vez que as plântulas apresentaram alta dominância apical (Kerbauy, 2004).

O efeito inibitório da citocinina na indução de raízes pode ser observado nos tratamentos com rizoma inteiro, onde a maior concentração resultou na inibição do número de raízes, o que corrobora os resultados de que as citocininas são responsáveis pela inibição do crescimento e divisão celular das raízes in vitro quando presentes em concentrações elevadas. (Taiz \& Zeiger, 2004). No entanto a adição de citocinina não influenciou no crescimento das raízes induzidas.

Com base nos resultados obtidos neste trabalho, verificou-se que, o processo de desinfestação e re-desinfestação de gemas laterais apresentou eficiência mediana no estabelecimento das culturas assépticas. A diminuição da dominância apical ocorreu em rizomas seccionados na presença de $1,0 \mathrm{mg} \mathrm{L}^{-1}$ BAP. O crescimento das plantas e das raízes não foi afetado pela diminuição da dominância apical. Sendo assim é possível a multiplicação in vitro de Etlingera elatior visando à produção massal de mudas de alta qualidade genética e fitossanitária, como fonte de matéria-prima para utilização terapêutica

\section{AGRADECIMENTO}

Os autores agradecem a UNIVALI pelo financiamento da pesquisa e ao Governo de Estado de Santa Catarina pela concessão da Bolsa de Pesquisa do Artigo 170.

\section{REFERÊNCIA}

DEBERGH, P.C.; MAENE, I.J. A scheme for the commercial propagation of ornamental plants by tissue culture. Scientia Horticulturae, v.14, p.335-45, 1981.

ENJALRIC, F.; CARRON, M.P.; LARDET, L. contamination of primary cultures in tropical areas: the case of Hevea brasiliensis. Acta Horticulturae, v.225, p.57-65, 1988. GEORGE, E.F. Plant propagation by tissue culture: the technology. 2.ed. Edington: Exegetics, 1993. 732p.

GORECKA, K. In vitro propagation of horse-radish (Cochlearia armoracia L.). Acta Horticulturae, n.212, p.6714, 1987.

GRATTAPAGLIA, D.; MACHADO, M.A. Micropropagação. In: TORRES,A.C.; CALDAS, L.S.; BUSO, J.A. Cultura de tecidos e transformação genética de plantas. Brasília: Embrapa. Serviço de Produção de Informação, 1998. 864p. HUSSEY, G. Totipotency in tissue explants and callus of some members of Liliaceae, Iridaceae and Amaryllidaceae. 
Journal Experimetal Botany, v.26, p.253-62, 1975a.

HUSSEY, G. Propagation of hyacinths by tissue culture. Scientia Horticulturae, v.3, p.21-8, 1975b.

JOLY, A.B. Botânica: uma introdução à taxonomia vegetal. 12.ed. São Paulo: Nacional, 1998. 777p.

KANE M.E. et al. Seasonal differences in ex vitro plant growth and corm formation between two micropropagated Sagittaria latifolia ecotypes. Acta Horticulturae, v.520, p.229-39, 2000.

KERBAUY, G.B. Fisiologia vegetal. Rio de Janeiro: Guanabara Koogan, 2004. 452p.

KHOSH-KHUI, M.; SINK, K.C. Micropropagation of new and old world rose species. Journal of the American Society for Horticultural Science, v.57, p.315-9, 1982. MARTINEZ, E.A.; TIZIO, R. Grapevine micropropagation through shoot tips and minicuttings from in vitro onenode cuttings. HortScience, v.24, n.3, p.513, 1989.

MURASHIGE, T.; SKOOG, F. A revised medium for rapid growth and bioassays with tobacco tissue. Physiologia Plantarum, v.15, p.473-97, 1962.

SCHWERTNER, A.B.S.; ZAFFARI, G.R. Micropropagação de Syngonium podophyllum Schott (Araceae). Revista Brasileira de Horticultura Ornamental, v.9, n.2, p.135-
42, 2003.

SIANI, A.C. et al. Desenvolvimento tecnológico de fitoterápicos: plataforma metodológica. Rio de Janeiro: Scriptorio Comunicação, 2003. 99p.

SOUZA, B.M. Retomada do ciclo celular induzida por variações dos teores endógenos de hormônios, açúcares e aminoácidos em primórdio de gema axilar de Ananas comosus L. (Merr.). 2006. 181p. Tese (Doutorado em Botânica) - Instituto de Biociências da Universidade de São Paulo, São Paulo.

TAIZ, L.; ZEIGER, E. Fisiologia vegetal. 3.ed. PortoAlegre: Artmed, 2004. 719p.

TANAKA, M. et al. Auxin controls local cytokinin biosynthesis in the nodal stem in apical dominance. Plant Journal, v.45, p.1028-36, 2006.

YUNES, R.A.; CALIXTO, J.B. Plantas medicinais sob a ótica da química medicinal moderna: métodos de estudo. Chapecó-SC: Argos, Editora Universitária UNOESC, 2001. 523p.

ZAFFARI, G.R. et al. Hormonal and histological studies related to in vitro banana bud formation. Plant Cell Tissue and Organ Culture, v.63, p.187-92, 2000. 